\title{
CAMINHOS PARA A EDUCAÇÃO AMBIENTAL ATRAVÉS DA EXTENSÃO E DA INTERDISCIPLINARIDADE: A EXPERIÊNCIA DO PROJETO TEMA EM FOCO
}

\author{
João Paulo Gomes de Vasconcelos Aragão ${ }^{1}$, Hugo Vinícius Gomes Dutra ${ }^{2}$
}

\begin{abstract}
RESUMO
A finalidade deste artigo é refletir caminhos para a educação ambiental a partir das concepções de extensão e interdisciplinaridade, observadas na experiência do projeto "Tema em foco: meio ambiente \& sociedade em questão", realizado no âmbito do Instituto Federal da Paraíba. Esta ação promoveu o debate e a reflexão acerca da questão ambiental e sua relação intrínseca com a sociedade. Para tanto, utilizou-se o modelo de debate do programa Roda Viva da TV Cultura, aplicando-o em diferentes unidades do IFPB. A proposta contribuiu na viabilização de ações interinstitucionais, na utilização do debate interdisciplinar como ferramenta de extensão e no fomento de estudos sobre temas ambientais. O projeto apontou a viabilidade de ações de educação ambiental nas unidades de ensino envolvidas, pautando-se nas concepções de extensão e interdisciplinaridade, além de ampliar os horizontes de discussão científica e cultural sobre meio ambiente. Os percentuais de aprovação dos debates, superiores a $80 \%$ nos Campi do IFPB participantes, registram o impacto positivo das ações do projeto tema em foco.
\end{abstract}

Palavras-chave: Educação ambiental; extensão; interdisciplinaridade.

\begin{abstract}
The purpose of this article is to reflect ways to environmental education based on the conceptions of extension and interdisciplinarity, observed in the experience of the project "Theme in focus: environment \& society in question", carried out within the framework of the Federal Institute of Paraíba. This action promoted debate and reflection on the environmental issue and its intrinsic relationship with society. To do so, we used the discussion model of Roda Viva TV Cultura program, applying it in different IFPB units. The proposal contributed to the feasibility of interinstitutional actions, the use of interdisciplinary debate as an extension tool and the promotion of studies on environmental issues. The project pointed to the feasibility of environmental education actions in the teaching units involved, based on the concepts of extension and interdisciplinarity, as well as broadening the horizons of scientific and cultural discussion about the environment. The percentages of approval of the debates, in excess of $80 \%$ in the Participating IFPB Campi, registered the positive impact of the project's theme actions in focus.
\end{abstract}

Key Words: Environmental education; extension; interdisciplinarity.

\section{INTRODUÇÃO}

A emergência da questão ambiental como tema central do mundo atual é resultado da soma de experiências científicas e culturais historicamente acumuladas a partir da relação sociedade - natureza, assim como da percepção humana sobre sua própria

\footnotetext{
${ }^{1}$ Licenciado em Geografia e especialista em Gestão Ambiental pela Universidade de Pernambuco. Mestre e doutorando em Desenvolvimento e Meio Ambiente pela Universidade Federal de Pernambuco.

${ }^{2}$ Estudante do curso Técnico em Informática Integrado ao Médio.
} 
interferência nos sistemas naturais e sociais que provocam, por sua vez, instabilidades nos arranjos ambientais da Terra (PORTO-GONÇALVES, 2011).

As disciplinas que compõem o currículo escolar, além de refletirem a evolução do saber humano, permitem o desenvolvimento de atitudes, concepções e valores necessários à vida, inclusive, no que concerne à conservação dos recursos naturais e à mitigação dos desníveis sociais e econômicos (FREIRE, 1996). Todavia, a estruturação do saber em estruturas ramificadas, rígidas e isoladas no currículo escolar pode comprometer a amplificação de valores e habilidades (LIBÂNEO, 2013), reduzindo-os a conceitos, os quais se desenvolvem de forma mais real quando ensinados "interdisciplinarmente".

Segundo Carvalho (2006) os conceitos são como lentes sobre nossa visão na realidade. De tão acostumados com estas lentes, torna-se comum o esquecimento de que estes mesmos conceitos não são o único caminho para a interpretação do mundo. Eles não esgotam as possibilidades de leitura, muito embora possam ser utilizados para contribuir no entendimento de sua totalidade.

O projeto de extensão "Tema em foco: meio ambiente \& sociedade em questão", concebido pelo Grupo de Pesquisa Geografia e meio ambiente - GEOAMB, promoveu debates em três Campi do Instituto Federal da Paraíba e conduziu estudantes, servidores e representantes das sociedades locais de cada Campus, enquanto unidade escolar, à reflexão e conhecimento das questões ambientais na contemporaneidade.

Nesta perspectiva, o projeto em tela desenvolveu-se enquanto caminho de reflexão de importantes temas da educação ambiental contemporânea, apoiando-se na integração das perspectivas de cotidiano e globalização mais as relações sociedade e natureza, primando pela discussão interdisciplinar e extensionista.

Com base nestes pressupostos o objetivo geral deste artigo é refletir as práticas de debates interdisciplinares e extensionistas como caminhos a uma educação ambiental contemporânea que integre reflexão com realidade, conhecimento com território e sociedade com ambiente.

\section{CAMINHOS PARA A EDUCAÇÃO AMBIENTAL ATRAVÉS DA EXTENSÃO E DA INTERDISCIPLINARIDADE}

$\mathrm{O}$ atual momento da humanidade, que é de crise, indica a educação ambiental como um caminho mais que meramente optativo e sim, como expõe Dias (2006), um processo indutório da transformação evolucionária da sociedade. Este aspecto deve ser, contudo, 
ampliado para todas as políticas de Educação que têm na realidade, em toda sua complexidade e envergadura, o intuito de conduzir a formação de um sujeito preocupado e participante em ações que promovam a sustentabilidade como forma racional e humana de Ser.

O contexto que certifica a importância desta nova indução como um processo, não só adequado, mas sim urgente ${ }^{3}$, é expresso, por exemplo, em realidades como a de municípios com falta de água e da existência de conflitos no mundo atual em virtude da escassez deste recurso. Dias (2006, p. 16) alerta que "hoje somos a espécie dominante na Terra e temos nos transformado em uma praga, devido ao nosso comportamento predatório, egoísta, imediatista, de querer tudo, sempre mais e agora".

Além disso, tem-se outras mazelas como as alterações climáticas, perda de solos férteis, desaparecimento de florestas e animais, desastres ambientais ligados à atividades de significativo impacto socioambiental, surgimento de novas doenças, aumento de inundações em cidades e perda de qualidade de vida, os quais, conforme Dias (2006), antes do progresso humano, estabelecem sob a sociedade um suicídio coletivo.

Segundo Aragão, et.al. (2011), as bases desta alienação mostram-se, contudo, muito lúcidas à medida que se identifica no discurso dos atores hegemônicos as justificativas que alimentam o atual modelo de produção e consumo. Este padrão de crescimento apoia-se ainda na manipulação das mentes realizando um modelo social que antes do desenvolvimento, gera em mão única e perversa, a exclusão e o opacamento das percepções de mundo.

Por empréstimo, confere-se a este contexto de crise o que Loureiro e Silva Neto (2016) explicam e Duarte (2004) denomina de "fetichismo da individualidade". Uma característica inconveniente para uma sociedade que precisa de demandas coletivas, inclusive, em prol de melhores condições socioambientais nas áreas urbanas e rurais. Loureiro e Silva Neto (2016) explicam que não é de se estranhar os tempos de relativismo epistemológico do presente, exemplificados em "propostas como "escola sem partido" e de criminalização daqueles que tratam de conteúdos vistos como políticos ou que problematizam e historicizam os costumes que regem a sociedade contemporânea" (2016, p. 42).

\footnotetext{
${ }^{3}$ Como diria o professor Paulo Freire "Mudar é dificil, mas é preciso e urgente".
} 
Esta incapacidade dos atores sociais, controlada pelos atores econômicos hegemônicos, resulta também na legitimação dos processos de degradação ambiental, uma vez que estes se tornam perceptíveis quando de sua ocorrência em forma de desastres, como o de Mariana-MG, estando as políticas de regulação e, principalmente, os direitos dos grupos sociais, na maior parte do tempo, tardados a segundo plano perante a envergadura econômica e política dos grupos sociais dominantes, representados pelos segmentos empresariais e corporações transnacionais e políticos.

Isto é constatado pela grande pressão que sofrem os recursos naturais ao terem sua capacidade de suporte suprimida, assim como os direitos de comunidades tradicionais, pelas imposições do capital. Tem-se na verdade uma relação "bancária" na qual os depósitos humanos a sua base natural são extraordinariamente inferiores às retiradas de recursos dos sistemas naturais. Nesta perspectiva, para Dias (2006, p. 17),

A perda da qualidade de vida ocorre de uma forma generalizada, em todo o mundo. Essa perda se traduz de forma diferenciada entre os diversos povos, grupos sociais e pessoas: vai desde a perda de uma cachoeira de água potável a um riacho que sumiu; de um recanto destruído à violência dos assaltos e do desemprego; do empobrecimento estético à erosão cultural; da insensatez das guerras à arrogância e ganância que as geram.

É neste contexto que a educação ambiental surge como um processo de reflexão e de revisão dos moldes de produção, do reconhecimento do Homem enquanto parte de um todo, do reencontro dos saberes e do comportamento humano frente à realidade e de meio de fomento a práticas de extensão pautadas no ensino e aprendizagem de temas relevantes ao cotidiano do sujeito ecológico e às ligações de seu lugar com o mundo, introduzindo uma perspectiva de totalidade.

Segundo o que Loureiro e Silva Neto (2016, p. 43) afirmam a respeito da totalidade, partindo da contribuição de Bottomore (2001),

o ser humano só pode ser compreendido e concebido na totalidade social em que os indivíduos e as múltiplas dimensões da vida humana se formam. A totalidade social, nessa linha de raciocínio, é um complexo estruturado e histórico, um complexo de complexos cujas partes específicas (totalidades parciais) estão relacionadas entre si, numa série de interrelações e determinações recíprocas que variam constantemente e se modificam.

Fio indutor para esta nova realidade, a educação enquanto processo social mais amplo deve incorporar este processo como parte de seu fazer, concebendo as necessidades internas e externas em todos aqueles meios onde se faça sua prática. Não alheia a esta "nova" condição, a escola surge como um destes contextos, todavia, dotada de ações 


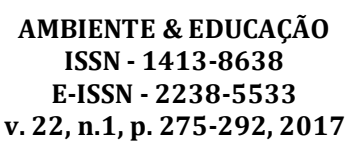

sistematizadas, quer em forma de aula, quer em forma de projetos e ações de extensão com a comunidade. Como bem lembram Loureiro e Silva Neto (2016, p. 43-44),

Não há sociedade sem educação, no sentido de que não há vida social sem o que a humanidade produziu (instrumentos, tecnologia, ciência, arte, condutas, costumes, valores, conhecimentos vários, ou seja, cultura) seja transmitido, reproduzido, ampliado, socializado e transformado. Compreender o mundo, ter consciência dele, interpretá-lo, "ser mundo", fazer juízo de valor e estabelecer códigos linguísticos são acontecimentos que se efetivam tão somente em sociedade [...]

A escola tem um papel cabal neste processo. Em sua função de realizar, em padrões formais, a educação e contribuir para a formação de cidadãos, constitui-se, a instituição escolar, em um espaço chave para o desafio da educação ambiental, contribuindo para a mudança de comportamentos frente à vida, realizando ações intencionais de reflexão e ação local, conforme as tramas territoriais que integra enquanto célula da sociedade.

De quais caminhos pode utilizar-se a educação ofertada nas instituições escolares? Dentre tantas possibilidades, acredita-se que a atividade extensionista seja uma possibilidade aberta ao diálogo com as formas de conhecimento mais próximas da comunidade. Nestes termos, a extensão é um meio para a realização do fazer escolar junto aos territórios de seus agentes, bem como uma forma de estender o saber científico à realidade da qual é indissociável (ARAGÃO; GOMES, 2017).

A extensão nesta perspectiva desenvolve-se não como uma ponte que articula a escola com o mundo externo, mas é ela própria um meio sistemático de sensibilidade da escola com sua realidade circundante e que viabiliza o diálogo entre distintos, porém, complementares saberes, conforme explicitam com Aragão e Gomes (2017). A dimensão ambiental da realidade pode neste processo ser explorada com fins a produzir um processo intencional e próximo à vida das pessoas, contribuindo para uma educação ambiental produzida por sujeitos que atuam na própria história, tendo voz e vez.

No que tange à educação ambiental, em sua matriz jurídica, esta pode ser considerada como coerente às demandas contemporâneas para a formação de um homem ecológico. Sua prática, no entanto, encontra-se lotada a um espaço utópico e ambíguo. Ferramenta fundamental para o desenvolvimento de uma gestão educacional atrelada aos valores ambientais, a Política Nacional de Educação Ambiental (BRASIL, 2016) apresenta diretrizes ao desenvolvimento da educação ambiental. O Art. $5^{\circ}$ da PNEA traz o texto

Na inclusão da Educação Ambiental em todos os níveis e modalidades de ensino, recomenda-se como referência os Parâmetros e as Diretrizes Curriculares Nacionais, observando-se: I - a transversalidade, continuidade e a permanência 
II - A adequação dos programas vigentes de formação continuada de professores.

Carvalho (2006) apresenta, de acordo com esta legislação, que são aspectos fundamentais a transversalidade, a continuidade e a permanência, além da interdisciplinaridade, e sua obrigatoriedade em todos os níveis de ensino, sendo sua composição em caráter de urgência e essencial no Ensino Fundamental.

Dentre estes aspectos, ressalta-se a relevância da interdisciplinaridade que, no processo de extensão, evidencia-se como processo inerente à sociedade e como fundamento para compreensão das tramas culturais, políticas e econômicas que compõem o cotidiano. Assim, acredita-se que a educação ambiental, por intermédio da extensão e da perspectiva interdisciplinar, precisa dar sentido às coisas, fazê-las perceptíveis aos olhos daqueles que as enxergam todos os dias e não daqueles que querem continuar a dominar.

Isto implica não idealizar o objeto, isto é, questão ambiental a ser debatida, mas sim, identificá-lo mediante o contato material com o mundo e este mundo sendo o cotidiano local, constituído pelo espaço no qual está a unidade de ensino e seus agentes. Conforme Libâneo et al (2005. p. 53), a escola contribui para o desenvolvimento de "conhecimentos, capacidades e qualidades para o exercício autônomo, consciente e crítico da cidadania". Para tanto, é preciso espraiar-se para o que há do mundo no lugar, observando as relações do lugar e de seus agentes com o mundo. A extensão, como já apontada, constitui um meio para isso e a interdisciplinaridade, por sua vez, uma forma de engajamento que não se limita ao elo entre disciplinas, mas expande-se no diálogo entre saberes, do científico ao popular.

A constituição deste processo efetivou-se entre teoria e prática, dimensões inseparáveis na produção da experiência e do conhecimento, expressados na concepção do espaço da intelectualidade e no espaço da praticidade. $\mathrm{O}$ primeiro configura o imaginário abstrato construído com o desenvolvimento interdisciplinar da Educação Ambiental, enquanto o segundo expressa por meio de vivências de todos os atores escolares com a realidade circundante da própria escola, o caráter extensivo da atividade.

Com este prisma, e pautando-se nas inter relações entre extensão e interdisciplinaridade para uma educação ambiental efetiva, propôs-se o projeto "Tema em foco: meio ambiente \& sociedade em questão". Acredita-se que por meio da relação entre o intelecto interdisciplinar e a extensão, mediando de forma direta a escola com a 


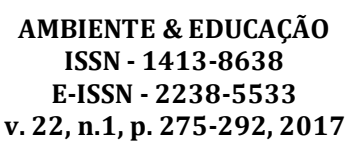

sociedade circundante, a educação ambiental é dada como processo de promoção de autonomia e conhecimentos mais amplos e significativos.

No âmbito dos Institutos Federais, no quais Ensino, Pesquisa e Extensão constituem pilares institucionais indissociáveis, a extensão constitui um caminho para a intersecção entre o intelecto e a praticidade, servindo como meio ao desenvolvimento de ações de educação ambiental de forma interdisciplinar. Assim, considera-se a definição de extensão dada pelo próprio Regimento Geral do Instituto Federal da Paraíba (IFPB, 2010) que, por sua vez, detalha

\begin{abstract}
Art.112 A extensão constitui um processo educativo, artístico-cultural, científico e tecnológico, articulado de forma indissociável à pesquisa e ao ensino, sendo realizada sob a forma de: I - Atendimento direto à comunidade, de forma interativa, por meio do ensino e da pesquisa, ou de outras formas de prestação de serviços especializados; II - Cursos, estágios ou atividades que se destinem à capacitação profissional; III - Prestação de assessoria, consultoria ou assistência técnica a instituições públicas ou organizações da sociedade civil; IV Promoção e participação em atividades técnico-científico, artístico-cultural e esportivo; V - Publicação e divulgação de conhecimentos técnicos e de trabalhos de interesse técnico-científico, artístico-cultural e esportivo; VI - Projetos que priorizem aspectos da realidade local ou regional; VII - Estímulo à criação artístico-cultural, científica e tecnológica;e VIII - Projetos que estimulem a preservação do meio ambiente e o desenvolvimento sustentável.
\end{abstract}

Tendo em vista a análise do projeto Tema em foco, destaca-se a relevância dos itens IV, V, VI e VIII no decurso do projeto em tela. Além disso, frisa-se a contribuição para uma reflexão interdisciplinar, seguindo a proposta apresentada por Fazenda (2012) que afirma a interdisciplinaridade não como categoria, mas sim como ação; não como síntese crua da realidade, mas como exercício de conhecimento; não como divórcio perante as disciplinas, mas do próprio desenvolvimento e diálogo destas.

Levando à frente estas proposições e inspirando-se em Leff (2009, p. 235), coube na concepção do projeto em tela inspirar entre os agentes sociais participantes um saber ambiental que

\begin{abstract}
constitui novas identidades e interesses, onde surgem os atores sociais que mobilizam a construção de uma racionalidade ambiental. Neste sentido, o saber ambiental se produz numa relação entre teoria e práxis. $O$ conhecer não se fecha em sua relação objetiva com o mundo, mas se abre à criação de sentidos civilizatórios. A qualidade de vida, como finalidade última da realização do ser humano, implica um savoir vivre, no qual os valores e os sentidos da existência definem as necessidades vitais, as preferências culturais e a qualidade de vida do povo.
\end{abstract}

Esta mudança, que não pode ser superficial, pois é na essência estrutural, traz para a escola contribuições ao seu processo formativo, bem como responsabilidades. No âmbito 
interno, para tanto, é preciso perceber a importância da continuidade do processo a partir da interatividade entre escola e comunidade, relação a qual encontra na extensão e na interdisciplinaridade meios para uma efetivação de propostas pedagógicas compromissadas com a formação do ser humano. A realização do projeto Tema em foco foi um demonstrativo desta possibilidade, em especial, de uma educação ambiental significativa e pensada a partir das tramas do cotidiano de cada Campus do IFPB participante na ação e dos debates que permitiram refletir em conjunto temas pertinentes a cada comunidade escolar.

\section{DO CAMINHO METODOLÓGICO DO PROJETO "TEMA EM FOCO: MEIO AMBIENTE \& SOCIEDADE EM QUESTÃO”}

Na perspectiva do interacionismo proposta por Vygotsky (2003), questionou-se até que ponto o debate sobre meio ambiente $\&$ sociedade, mediado pelo diálogo orientado e discursivo com o outro, contribui para o desenvolvimento intelectual do ser humano e para a viabilização do processo de educação ambiental?

Entenda-se "o outro" não apenas como a figura do que está a nossa frente, mas nos termos deste trabalho, os agentes que compõem a comunidade escolar, desde estudantes e servidores do IFPB Campus Esperança, até líderes sindicais, professores e gestores municipais, pais de estudantes, dentre outros. O "outro" é assim a pessoa e nesta a experiência e saber cotidiano, cujo diálogo entre um processo de interdisciplinaridade com os saberes sistematizados reproduzidos na unidade escolar, por intermédio da extensão.

O método da proposta também se assentou na ideia de interdisciplinaridade proposta, dentre outros, por Fazenda (2012) e na pedagogia da autonomia de Freire (1996), bem como na base teórica sobre extensão, defendida por Aragão e Gomes (2017). A concepção pedagógica sócio cultural abrangeu a proposta empírica mencionada, tendo em vista a consolidação de habilidades mentais em sujeitos autônomos e historicamente situados (LIBÂNEO, 2013). Isto implica uma construção metodológica aberta às transformações didáticas e epistemológicas inerentes ao movimento pedagógico do projeto e às demandas de seus participantes no que diz respeito aos dilemas socioambientais da contemporaneidade.

A escolha do tema dos debates sempre esteve relacionada aos interesses dos agentes que compõem a comunidade do Campus que recebe o projeto, caracterizando, desde a 


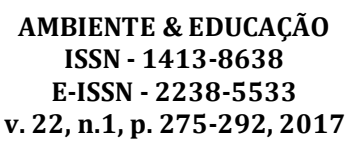

definição do tema um processo de extensão com a comunidade e de troca de saberes com esta. Desta forma, a designação dos temas relativos a meio ambiente visava corresponder aos anseios da comunidade escolar em discutir a relação meio ambiente e sociedade, cotidiano e território.

Os debates eram realizados com a presença de um convidado que, por intermédio de sua experiência de vida e profissional, respondia às questões dos agentes escolares do Campus, os quais levavam em conta as questões observadas a partir de seu cotidiano. Já o modelo de organização do local onde ocorria o debate era inspirado na proposta freiriana de discussão em círculo (Figura 1) e visava dispor os participantes em condição de participação efetiva, interagindo não só com o convidado, mas externando a todos os presentes sua forma de concepção da temática.

Figura 1. Modelo de distribuição dos participantes no local do debate do Tema em Foco.

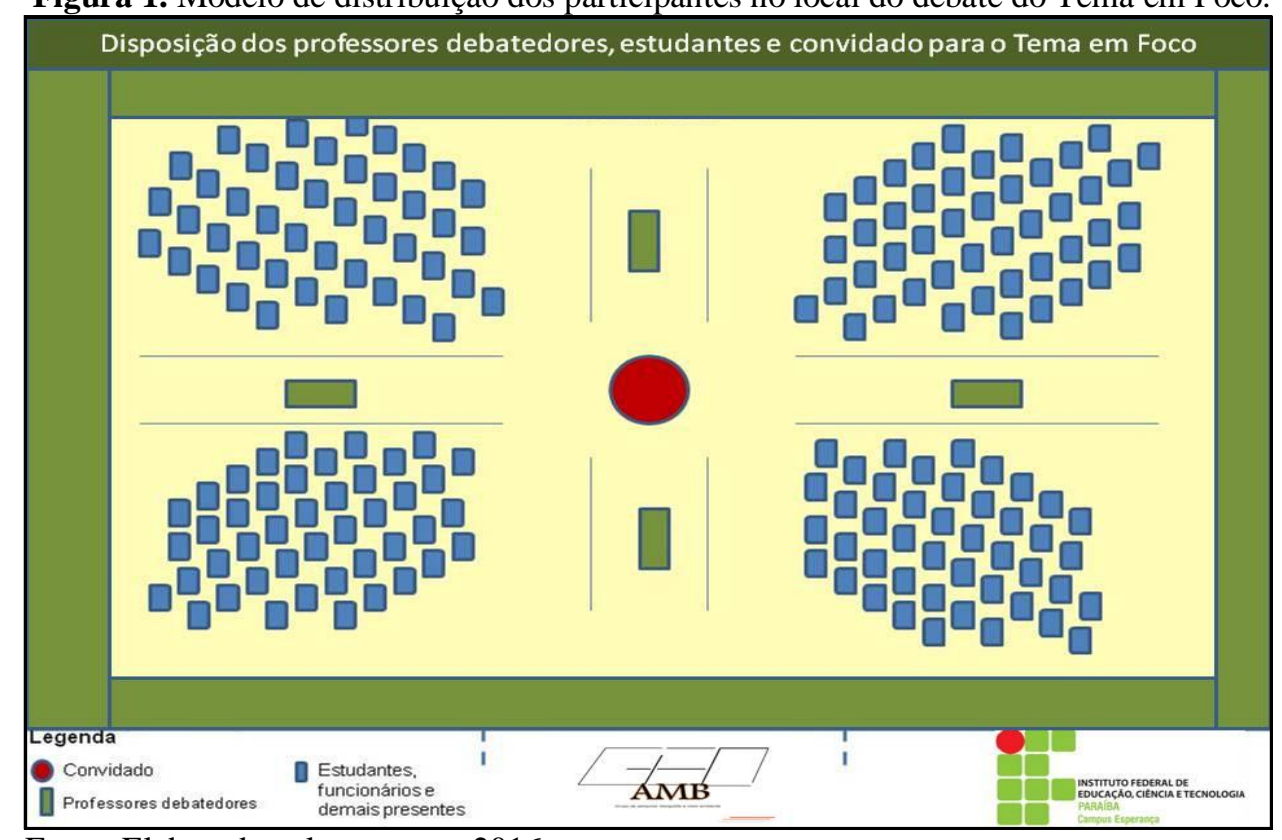

Fonte: Elaborado pelos autores, 2016.

A metodologia proposta sustentou-se na relação empírica pergunta - resposta / debate - reflexão (P-R/D-R) inspirada na dinâmica do programa "Roda Viva" da TV Cultura. A concepção pedagógica sócio cultural proposta por Libâneo (2013) foi direcionada neste projeto para o fomento de uma educação preocupada com as questões ambientais alicerçadas no cotidiano e nas relações sociedade natureza do lugar (CARVALHO, 2006).

A metodologia, todavia, iniciava-se com antecedência ao debate. A proposta devia ser inspirada ao longo das semanas antecedentes à discussão. A construção deste 
"foco temático" era conduzida mediante a provocação do tema junto a estudantes, servidores e representantes da sociedade local, seguindo as etapas processuais sugeridas, quais sejam, observação da realidade local e consulta a representantes da sociedade, trato da temática em sala de aula, convite a representantes da comunidade escolar e palestrante, além da elaboração de questões pelos professores, estudantes e membros da comunidade.

O processo avaliativo de cada debate, por sua vez, era mediado pela opinião dos agentes escolares. Apesar de consentir a avaliação como processo qualitativo eram distribuídas fichas de avaliação dos aspectos 1. Didático/interdisciplinar, 2. pedagógico, 3. temático, 4. extensionista e 5. intelectual. Concebeu-se como meta para o projeto em tela o percentual de 70 a $100 \%$ de aprovação nos dois primeiros debates e de 80 a $100 \%$ nas três últimas ações do tema em foco (Quadro 01).

Os índices acima eram obtidos com a aplicação do questionário com percentual mínimo de $20 \%$ dos estudantes presentes na realização do Tema em Foco, todos os professores debatedores, $10 \%$ dos servidores do Campus que estivessem recebendo o Tema em Foco e que se fizessem presentes durante a realização dos trabalhos e $10 \%$ dos representantes da sociedade local.

Quadro 1. Índices desejáveis de aprovação para os debates o Tema em foco.

\begin{tabular}{|cl|c|c|}
\hline Aspecto avaliado & $\begin{array}{c}\text { Índice desejado de } \\
\text { aprovação (Entre bom e } \\
\text { excelente) no primeiro e } \\
\text { segundo "Tema em Foco" }\end{array}$ & $\begin{array}{c}\text { Índice desejado de } \\
\text { aprovação (Entre bom e } \\
\text { excelente) no terceiro, } \\
\text { quarto e quinto "Tema em } \\
\text { Foco" }\end{array}$ \\
\hline 1. & Didático/interdisciplinar & De 70 a $100 \%$ & De 80 a $100 \%$ \\
\hline 2. & Pedagógico & De 70 a $100 \%$ & De 80 a $100 \%$ \\
\hline 3. & Temático & De 70 a $100 \%$ & De 80 a $100 \%$ \\
\hline 4. & Extensionista & De 70 a $100 \%$ & De 80 a $100 \%$ \\
\hline 5. & Intelectual & De 70 a $100 \%$ & De 80 a $100 \%$ \\
\hline
\end{tabular}

Fonte: Elaborado pelos autores, 2016.

Apesar da utilização deste instrumento quantitativo frisa-se a concepção de avaliação como um processo contínuo que se baseia no acompanhamento das ações e na revisão constante de seus sentidos e direções. Nesta perspectiva, o projeto "Tema em Foco" inspirou-se na capacidade de aperfeiçoamento inerente ao fazer humano, fundamentado na crítica do conhecimento, da auto avaliação e no movimento da história das sociedades (LIBÂNEO, 2013). 


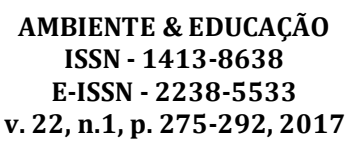

Os Campi selecionados para participar do projeto foram escolhidos com base na existência de um ou mais representante do grupo de pesquisa Geografia e meio ambiente (Geoamb), haja vista que o processo de organização dos debates demandava a participação de um professor representante do Campus, atento às demandas da comunidade local, bem como na articulação ao processo de organização do debate. Assim, foram selecionados os Campi Santa Rita, Itabaiana, Esperança, Princesa Isabel e Picuí, todos do IFPB.

\section{OS EFEITOS DOS DEBATES NA PERSPECTIVA DA EXPERIÊNCIA VIVIDA E DA EDUCAÇÃO AMBIENTAL}

A realização de cada debate e a expectativa dos efeitos que os mesmos poderiam gerar sempre foi considerável. As alegrias e dificuldades, naturalmente, surgiram ao longo do processo, possibilitando novas aprendizagens. De todas as dificuldades ganhou destaque ao longo do processo a inviabilidade de realização dos debates em dois dos Campi inicialmente escolhidos: Princesa Isabel e Picuí.

Em ambas as situações foram impositivas a ordem dos fatos atuais e interpessoais. Dificuldades financeiras, de gestão e o movimento grevista intensificado no segundo semestre de 2016 haja vista as repercussões das propostas do governo federal com a Proposta de Emenda Constitucional (PEC) 241, depois denominada de PEC 55, mais a Medida Provisória (MP) 746 da Reforma do Ensino Médio, além de questões de saúde que afetaram a equipe participante do projeto, inviabilizaram as expectativas de realização do Tema em Foco em Princesa Isabel e em Picuí, infelizmente, não efetivadas. Nos outros Campi, contudo, a ações do projeto foram efetivadas, obtendo bons resultados.

Após a realização dos debates, em todos os Campi, foram aplicados os questionários avaliativos dos debates realizados. Em Santa Rita, o percentual de aprovação "bom" e "excelente" superou o índice de 95\% em todos os aspectos aferidos. Em Itabaiana, apenas para os aspectos didático/interdisciplinar e intelectual, o índice de aprovação foi de 80\%, alcançando os $100 \%$ nos demais aspectos. Já em Esperança, os índices alcançaram $100 \%$ em todos os critérios, com exceção do extensionista. Tributam-se estes resultados positivos à relevância dos temas discutidos com o contexto socioambiental no qual se inseriam os participantes, bem como pelo caráter interdisciplinar e extensivo da atividade.

Em todos os debates promovidos pelo projeto "Tema em foco" (Figura 2) o diálogo entre saberes foi identificado como necessidade imperativa, haja vista os temas discutidos 


\section{AMBIENTE \& EDUCAÇÃO}

ISSN- 1413-8638

E-ISSN - 2238-5533

v. 22, n. 1, p. 275-292, 2017

serem relevantes no cotidiano de cada Campus. A interdisciplinaridade neste processo era consequência de uma necessidade do próprio objeto em debate, não se restringindo a interpretações multidisciplinares dispostas em forma de recortes de conhecimento científico, uma vez que era fundamental a concepção popular sobre os temas. Mesmo sendo conduzida por um grupo de pesquisa localizado na Geografia, a discussão sobre meio ambiente, reclamava o diálogo entre distintas áreas de conhecimento.

Figura 2. Fotos dos debates realizados pelo projeto "Tema em foco",

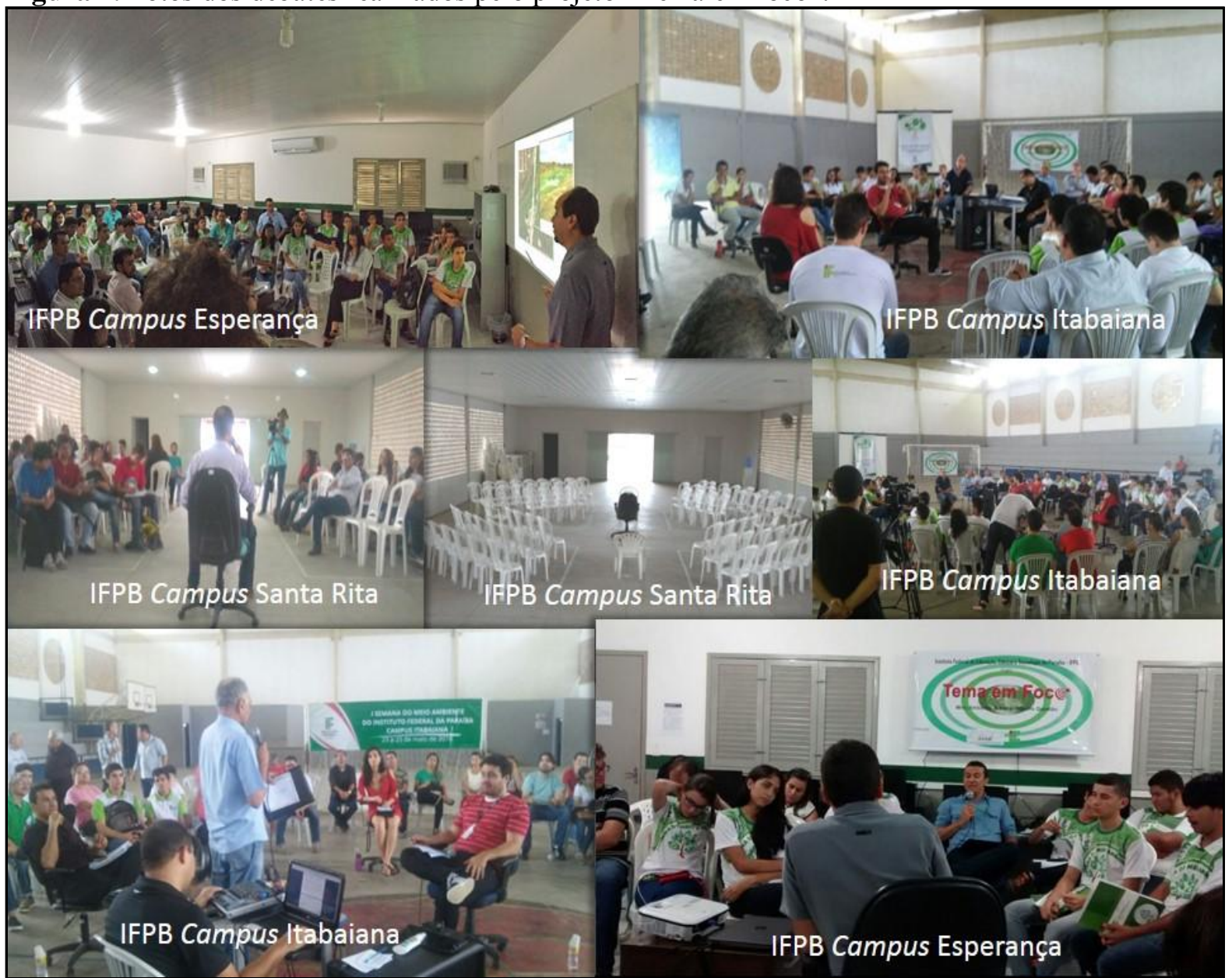

Fotos: Os autores, 2016.

Não raro, esta ação - reflexão tornou-se viável com a extensão, enquanto processo intencional e sistematizado de relações entre escola e comunidade. Foi com base na proposta de uma extensão preocupada com o atendimento direto à comunidade, de forma interativa, por meio do ensino e da pesquisa, e na importância da participação da comunidade nos processos escolares que a proposta do projeto Tema em foco fez-se prática. Este fato tornou-se ainda mais relevante, uma vez que os Campi Santa Rita, Itabaiana e Esperança, constituam 


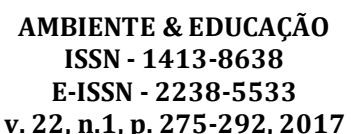

unidades recentemente implantadas, fato este corroborava a necessidade de diálogo com a comunidade com fins ao entendimento das reais questões entre o meio ambiente e a sociedade local.

No Campus do IFPB Santa Rita, a discussão sobre "Atividade canavieira em terras de águas minerais" reuniu conhecimentos técnicos do processo industrial de exploração da cana de açúcar com noções de biodiversidade, conservação ambiental, história local e regional e produção do espaço brasileiro. A presença de estudantes, servidores foi tão importante quanto à participação de representantes locais, como a instituição social responsável por projetos de reciclagem de lixo no município de Santa Rita, Cooperativa de reciclagem do Marcos Moura - COOREMM.

As questões apresentadas por todos participantes permitiram ampliar os horizontes teóricos sobre, mas principalmente, fomentar as relações extensionistas entre o Campus Santa Rita e sua comunidade. O debate constituiu-se num exercício de reflexão interdisciplinar, outrossim, num processo de extensão baseado nas questões ambientais que constituem o território de atuação do Campus.

Esta experiência repetiu-se no IFPB Campus Itabaiana, onde o debate sobre meio ambiente e indústria inspirou questões cujas reflexões migravam da sociologia à biologia, da Geografia à Economia, das ciências às hábitos da população local, discutindo subtemas como o capitalismo ético, a relevância das indústrias para o desenvolvimento dos arranjos produtivos locais e os impactos negativos da atividade industrial sobre os rios. A presença de representantes da indústria e de movimentos ambientais do município aferiu significado na realidade local para os temas em discussão.

Compondo as atividades da I Semana do Meio Ambiente no Campus Esperança, o debate do projeto Tema em foco sobre crise hídrica tornou mais perceptiva a envergadura deste problema em Esperança e no Brasil. A escolha do tema por si mesma já expressou o resultado de uma atividade extensiva à medida que no Campus Esperança os preparativos para o debate envolveram uma incessante consulta a agentes locais, como por exemplo, os representantes de secretarias do governo municipal e agentes públicos da Empresa de Assistência Técnica e Extensão Rural / Emater-PB).

No debate, saberes relativos à gestão dos recursos hídricos, economia da água, propriedades químicas e a geopolítica dos recursos hídricos, foram alguns dos temas explorados e tratados à luz de saberes comuns a muitas áreas do conhecimento. A participação de representantes do poder público municipal, especialmente, das secretarias 
de Educação e Agricultura, Recursos Hídricos e Meio Ambiente, conferiu destaque para o tema tratado e ampliou a relação do Campus com agentes sociais envolvidos com a gestão das águas.

Além destes aspectos os debates do tema em foco contribuíram para a) ampliação dos diálogos entre pesquisadores e extensionistas de vários Campi do IFPB, b) aproximação entre representantes das sociedades locais em cada Campus participante, c) inovação metodológica através da prática de debates em círculo freiriano e dinâmica "roda viva", e d) subsídio a novas iniciativas de pesquisa e extensão, e) fomento a ações interdisciplinares nos Campus que realizaram o debate, e f) viabilização de ações reflexivas de educação ambiental com forte vinculação aos territórios de atuação de cada Campus participante, a partir dos pressupostos sobre extensão e interdisciplinaridade.

A experiência empírica dos debates possibilitou, contudo, o aprendizado e auto correção de procedimentos que, por mais simples, implicam na revisão interna da proposta e de sua reorganização a cada novo debate realizado. O Tema em Foco em Santa Rita, onde ocorreu a primeira atividade do projeto, permitiu delinear o melhor uso do tempo, por exemplo. Foi sugerida para antes do debate uma exposição de 20 minutos pelo professor convidado sobre o Tema "atividade canavieira em terra de águas minerais". A ideia foi acatada, porém, devido, a ausência de um planejamento sobre o controle do tempo desta exposição, o uso do tempo foi para além do desejado, perfazendo um total de 50 minutos.

A partir disto, foi delineado para todos os debates do Tema em Foco que a fala inicial do professor convidado não passaria de 20 minutos, haja vista ser o debate com rodadas de perguntas o fio condutor da metodologia e didática do projeto. Esta experiência seria reproduzida com sucesso nos debates do Tema em Foco realizados em Itabaiana e Esperança, posteriormente.

Apesar de previstos na proposta inicial, foi possível constatar que a escolha de professores convidados para o debate, o preparo anterior dos estudantes para as discussões, o horário de realização, o espaço físico a ser utilizado e a operação logística de coleta de assinaturas e emails deveria ser mais atenciosa e trabalhada, realizando-as com base na experiência acumulada ao longo do projeto.

No Tema em Foco do Campus Itabaiana, por exemplo, verificou-se que a realização do debate como parte de um evento local (neste caso, a Semana do meio ambiente) comprometeu algumas tarefas simples, como o levantamento das assinaturas de presença e 


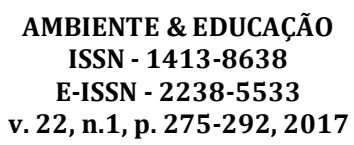

emails dos participantes. Com base nesta experiência, e apesar de as assinaturas terem sido colhidas posteriormente e enviadas para a coordenação do projeto, tratou-se com mais atenção o debate que ocorreria na pauta de atividades de um evento local, especialmente, quando os representantes locais do Tema em Foco estavam igualmente envolvidos na organização do evento local, evitando assim o acúmulo de atividades em curto período e o comprometimento da organização do Tema em Foco (tal como no Campus Esperança).

O cuidado com o horário de realização do Tema em Foco, por sua vez, indicou a importância de considerar os horários de início e término haja vista a locomoção de estudantes que residem em outras cidades, fato identificado em Esperança, onde as atividades estenderam-se até as $18 \mathrm{~h} 00 \mathrm{~min}$. Ainda que ocorresse como atividade da I Semana do Meio Ambiente do Campus Esperança e que fatores alheios à coordenação do evento, principalmente, o atraso da programação geral do evento em tela tenha atrapalhado a dinâmica da atividade, o fato foi observado e registrado.

Tanto quanto a dimensão temporal inferiu maiores cuidados, tendo em vista a qualidade do debate, viu-se no aspecto físico um fator relevante para o debate, especialmente ao conforto dos participantes e organização do layout do espaço utilizado. No Campus Esperança, o pequeno espaço utilizado referente ao laboratório de Informática deste Campus, não foi totalmente adequado às demandas da proposta, sobretudo, quando comparado aos espaços físicos utilizados em Santa Rita e Itabaiana, satisfatórios neste quesito. Por isso, seguindo a experiência destes últimos dois Campi, atestou-se a necessidade de, nos casos em que o Campus não apresenta condições de realizar o Tema em Foco em suas dependências físicas, sejam elas permanentes ou provisórias, utilizar espaço físico adequado disponível na cidade onde se situa o Campus.

Com base nestas experiências, acredita-se que conduzir o processo de aprendizagem sobre as questões ambientais pertinentes aos arranjos territoriais de cada Campus do IFPB participante, em sua complexidade e envergadura, promovendo o debate enriquecedor de ideias de forma autônoma, torna a instituição social de educação escolar (IFPB) competente para promoção das condições sistemáticas mais amplas de realização do ensino e da aprendizagem de importantes temas e ações de educação ambiental.

Isto demanda ações internas à proposta, como os trâmites de planejamento de um projeto de extensão, o qual não teria conferido o mesmo resultado não fossem as 
participações dos representantes da sociedade nos debates, assim como no processo de identificação das principais questões ambientais do cotidiano dos agentes escolares.

A relação deste projeto com as expectativas sociais de uma instituição de ensino pública tais quais os Institutos Federais, também exige preocupação sobre o processo de construção de conhecimento que se deseja. Neste sentido, a busca por debates interdisciplinares foi considerada o caminho mais adequado, uma vez que, a partir da extensão, seria possível colocar em diálogo não apenas as disciplinas escolares, mas estas em conjunto com o saber popular de cada comunidade, representada pelos agentes sociais participantes nos debates.

Sem embargos, segundo Libâneo (2013) cumpre às instituições de ensino formal o dever de pensar os meios e condições para alcançar seus objetivos para com a aprendizagem. Em conformidade aos parâmetros legais esse processo deve pautar-se em, dentre outras referências, na interdisciplinaridade do conhecimento e na transversalidade de certos temas, como a cultura, a sexualidade, as artes e o meio ambiente (BRASIL, 1997), sendo este último explorado com diferentes ênfases em cada debate do projeto Tema em foco.

Citando Mello (1982, p. 14), reforça-se o ideal de que "agir dentro da escola é também agir na sociedade da qual ela não está separada" o que mais uma vez conclama a conveniência de atividades extensionistas. Sem dúvidas, a escola, o instituto e a universidade, reúnem sistematicamente as expectativas de formação intelectual e humana de uma sociedade que almeja o exercício da cidadania como prática efetiva, conforme lembra Silke (1996).

Para tanto, a discussão do tema matriz "a questão ambiental e sua relação intrínseca com a sociedade", mediada pelas concepções de extensão e interdisciplinaridade, foi consolidada como contribuição basilar deste projeto, em especial, no que tange ao fomento de caminhos para uma educação ambiental atrelada ao lugar e à complexidade das relações sociedade - natureza na contemporaneidade. Cada realização do "Tema em Foco" viabilizou a reflexão sobre distintos desdobramentos da vida produtiva, social, e econômica aonde cada Campus do IFPB participante conduz seriamente seu papel de formação numa sociedade calcada a pensar seu contexto socioambiental. Longe de estabelecer conclusões, este projeto vislumbrou, acima de tudo, apontar caminhos epistemológicos para a educação ambiental do século XXI. 


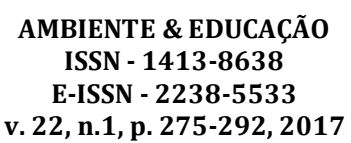

\section{CONSIDERAÇÕES FINAIS}

Os debates promovidos pelo projeto Tema em foco ampliaram os horizontes de discussão científica e cultural sobre meio ambiente, fomentando análises baseadas na extensão e na interdisciplinaridade ligadas à realidade das questões ambientais na sociedade local, sem perder, todavia, os nexos com as disciplinas escolares, fundamentais para construção do saber sistematizado, portadoras de instrumentos teóricos e metodológicos que precisam ser respeitados. O desafio posto foi o da dialogicidade destas áreas consigo mesmas e com o saber popular, representado na participação de agentes externos a cada Campus do IFPB participante.

O nexo principal deste projeto foi, sem embargos, a contribuição de cada Campus que, mediante esforços assumidos por companheiros (as), atuaram em consórcio para a realização dos debates, visando a tarefa basilar da aprendizagem em diálogo com as tramas ambientais efervescentes em cada configuração territorial dos Campi participantes desta iniciativa. A partir destas dialogicidades, foi possível contribuir para o processo de ensino e aprendizagem em cada Campus, bem como perceber as dificuldades e desafios que uma proposta assentada na extensão e na interdisciplinaridade, na interinstitucionalidade e na relação com o cotidiano local, apresenta.

Por meio desta experiência foi possível ainda apontar caminhos para a educação ambiental que se pretende alçar, especialmente no âmbito dos Institutos Federais, enquanto unidades de ensino escolar, na continuidade deste século XXI. A extensão, interdisciplinaridade e a interinstitucionalidade, por mais singulares que sejam, constituemse em subsídios centrais e que devem ser postas em diálogo para uma ação baseada no entendimento da expressão local, dos arranjos territoriais e cotidiana, das relações entre sociedade e natureza. A construção de uma totalidade no pensamento deve, pois, constituir-se de alicerces na realidade vivida e no caminho que se percorre em sociedade. $\mathrm{O}$ projeto em tela não inaugurou esta reflexão, mas reforçou sua necessidade, vitalidade e viabilidade.

\section{REFERÊNCIAS}

ARAGÃO, João Paulo Gomes de Vasconcelos; SANTOS, Karolina Maria Bezerra; SILVA, Marlene Maria da. "Gestão ambiental e escolas: a construção de uma atitude ambiental". Revista Ambiente \& Educação. Rio Grande, Vol. 16 (n.2), 2011, p. 27-40. 
ARAGÃO, João Paulo Gomes de Vasconcelos; SILVA, Luciano Gomes da. "Ação extensionista em Campus de Institutos Federais recentemente implantado: reflexões a partir de um projeto de extensão". Revista Práxis: saberes da extensão. João Pessoa, Vol. 5 (n.8), 2017, p. 101-121.

BOTTOMORE, Tom. Dicionário do pensamento marxista. Rio de Janeiro: Jorge Zahar Editor, 2001.

BRASIL. Parâmetros Curriculares Nacionais. Brasília: MEC/SEC,1997.

Política Nacional de Educação Ambiental. Lei no 9.795 de 27 de abril de 1999, que dispõe sobre a educação ambiental, institui a Política Nacional de Educação Ambiental e dá outras providências. In: http://www.planalto.gov.br/ccivil_03/Leis/L9795.htm. Acesso em 15 de agosto de 2016.

Política Nacional de Meio Ambiente, Lei No 6.938 de 31 de agosto de 1981, dispõe sobre a Política Nacional do Meio Ambiente, seus fins e mecanismos de formulação e aplicação, e dá outras providências. In: http://www.planalto.gov.br/ccivil_03/Leis/L6938.htm. Acesso em 15 de agosto de 2016.

CARVALHO, Isabel Cristina de M. Educação ambiental: a formação do sujeito ecológico. São Paulo: Contexto, 2006.

DIAS, Genebaldo Freire. Educação e Gestão Ambiental. São Paulo: Gaia, 2006.

DUARTE, Newton. Crítica ao fetichismo da individualidade. São Paulo: Autores Associados, 2004.

FAZENDA, Ivani. Interdisciplinaridade: História, teoria e pesquisa. Campinas, SP: Papirus, 2012.

FREIRE, Paulo. Pedagogia da autonomia. São Paulo: Paz e Terra, 1996.

INSTITUTO FEDERAL DA PARAÍBA. Regimento geral do IFPB. João Pessoa: IFPB, 2010.

LEFF, Enrique. Saber Ambiental: sustentabilidade, racionalidade, complexidade, poder. Rio de Janeiro: Vozes, 2009.

LIBÂNEO, José Carlos; OLIVEIRA, João Ferreira; TOSCHI, Mirza Seabra. Educação Escolar: políticas, estrutura e organização. São Paulo: Cortez, 2005.

LIBÂNEO, José Carlos. Didática. São Paulo: Cortez, 2013.

LOUREIRO, Carlos Frederico B.; SILVA NETO, José Garajau da. "Indivíduo social e formação humana: fundamentos ontológicos de uma educação ambiental crítica". Revista de Educação Ambiental. Rio Grande, Vol. 21 (n.1), 2016, p. 41 - 58.

MELLO, Guiomar Namo. Magistério de $\mathbf{1}^{\mathbf{0}}$ grau: da competência técnica ao compromisso político. São Paulo: Cortez, 1982.

PORTO-GONÇALVES, Carlos Walter. A globalização da natureza e a natureza da globalização. Rio de Janeiro: Civilização brasileira, 2011.

SILKE, Weber. O professorado e o papel da educação na sociedade. Campinas-SP: Papirus, 1996.

VYGOTSKY, Lev. Pensamento e linguagem. São Paulo: Martins Fontes, 2003. 